\title{
LUCHAS COSTEÑAS POR LOS DERECHOS TERRITORIALES Y EL CONTROL DE LOS EMERGENTES ESPACIOS MEDIÁTICOS DE NICARAGUA
}

\author{
COSTEÑO STRUGGLES FOR LAND RIGHTS AND THE CONTROL \\ OF EMERGENT MEDIA SPACES IN NICARAGUA
}

Julie Cupples

Kevin Glynn

Recibido: 04/05/2018 - Aceptado: 18/05/2018

\begin{abstract}
Resumen
Este artículo trata de las respuestas mediáticas a la crisis actual en la Costa Caribe de Nicaragua y los retrocesos a las luchas regionales por la autonomía y los derechos a la tierra. Proporciona un panorama detallado del actual conflicto en el Caribe Norte, en particular cómo las acciones violentas de los colonos ilegales están acelerando la inseguridad y la degradación ambiental y cómo organizaciones de derechos humanos como CEJUDCHAN están utilizando espacios como YouTube para responder a esta situación. También esboza las luchas por el pueblo Rama Kriol en el Caribe Sur en contra del canal interoceánico. A partir del concepto de sociología de ausencias de Boaventura de Sousa Santos, el trabajo explora la inacción, la indiferencia y el engaño del Gobierno, así como la producción, distribución y visibilidad de los medios de comunicación de base.
\end{abstract}

Palabras clave: Nicaragua, medios de comunicación, autonomía, derechos a la tierra, decolonialidad.

\begin{abstract}
This article explores media representations of the current crisis on the Caribbean Coast of Nicaragua and the setbacks to regional struggles for autonomy and land rights posed by this crisis. It provides a detailed analysis of the current conflict in the North Caribbean region, and focuses in particular on how the violent actions of illegal settlers are accelerating insecurity and environmental degradation there, and how organizations such as CEJUDCHAN are using media spaces like YouTube to respond to and intervene in this situation. It also outlines the Rama Kriol people's struggles against new plans for an interoceanic canal in the South Caribbean. We draw on Boaventura de Sousa Santos' concept of a "sociology of absences" to analyze both the Nicaraguan government's inaction, indifference and deceit in the face of
\end{abstract}


indigenous and campesino opposition, and popular practices of oppositional media production and circulation.

Keywords: Nicaragua, media, autonomy, land rights, decoloniality.

\section{Introducción ${ }^{1}$}

Si alguien pasa por el reparto El Carmen, situado en Managua, donde se encuentran la casa y sede presidencial del mandatario de Nicaragua, Daniel Ortega, se encontrará con una exagerada presencia policial. En los alrededores del muro que protege la casa presidencial, hay 12 puestos de control de la policía con al menos dos oficiales estacionados en cada uno, ellos le proporcionan al presidente 24 horas de protección (Almanza y Cruz). Los residentes en esta zona requieren permiso para entrar, salir y recibir visitantes.

Esta seguridad supera muchísimo las medidas tomadas por presidentes anteriores; quizás Ortega tiene razones para temer por su vida. Desde su regreso al poder, en 2006, él y su esposa (ahora vicepresidente Rosario Murillo) han desmantelado la democracia de Nicaragua a través de una serie de mecanismos. Estos incluyen el control de las cuatro ramas del gobierno (ejecutivo, legislativo, judicial y electoral), el control del ejército y la policía, la participación en prácticas electorales fraudulentas, el clientelismo, el despido de personal y de políticos electos que critican al gobierno y el uso frecuente de la policía antidisturbios para anular las protestas.

Han comprado, cooptado o silenciado los medios de comunicación independientes y han creado un clima de miedo que provoca la autocensura. Existe un bloque de poder autoritario sandinista, encabezado por Ortega y Murillo, en alianza con el Consejo Supremo Electoral, el Poder Judicial, la mayor parte de la Asamblea Nacional, las fuerzas de seguridad y gran número de medios de comunicación. Este bloque de poder trabaja de forma colectiva para ignorar o reprimir cualquier evento, proceso o reclamo que represente un desafío a la hegemonía orteguista.

El Gobierno maneja un discurso antiimperialista, socialista y cristiano, pero trabaja estrechamente con los intereses capitalistas. Actualmente se está trabajando en la construcción de un canal interoceánico de USD 50000 millones con inversiones extranjeras chinas. El canal propuesto es un megaproyecto altamente neoliberal y colonial que socavará la soberanía de Nicaragua, desplazará a miles de campesinos de sus tierras y producirá una destrucción ambiental dramática e irreversible.

Los nicaragüenses soportan múltiples formas de inseguridad, pobreza persistente y tensión política, pero el discurso del Gobierno abarca una retórica alegre y triunfante de amor, paz, prosperidad, solidaridad y felicidad; y evade el compromiso con los problemas más difíciles. Esta evasión es tal vez mejor representada por las carteleras omnipresentes que llevan la cara de Daniel Ortega (Figura 1) y los llamados "árboles de la vida" 
que recorren las calles de Managua (Figura 2). ${ }^{2}$ Sin embargo, existen pruebas de que el consentimiento para la versión orteguista de la realidad es cada vez más difícil de asegurar.

Figura 1

VALLA PUBLICITARIA DE DANIEL ORTEGA

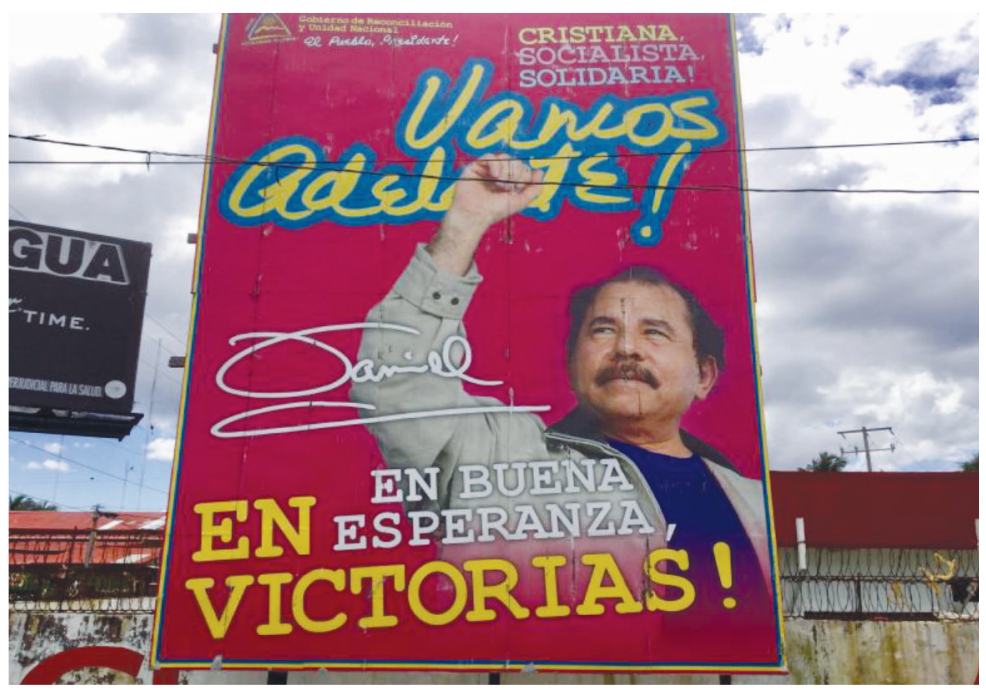

Fuente: Elaboración propia.

Figura 2

ÁRBOLES DE LA VIDA EN MANAGUA

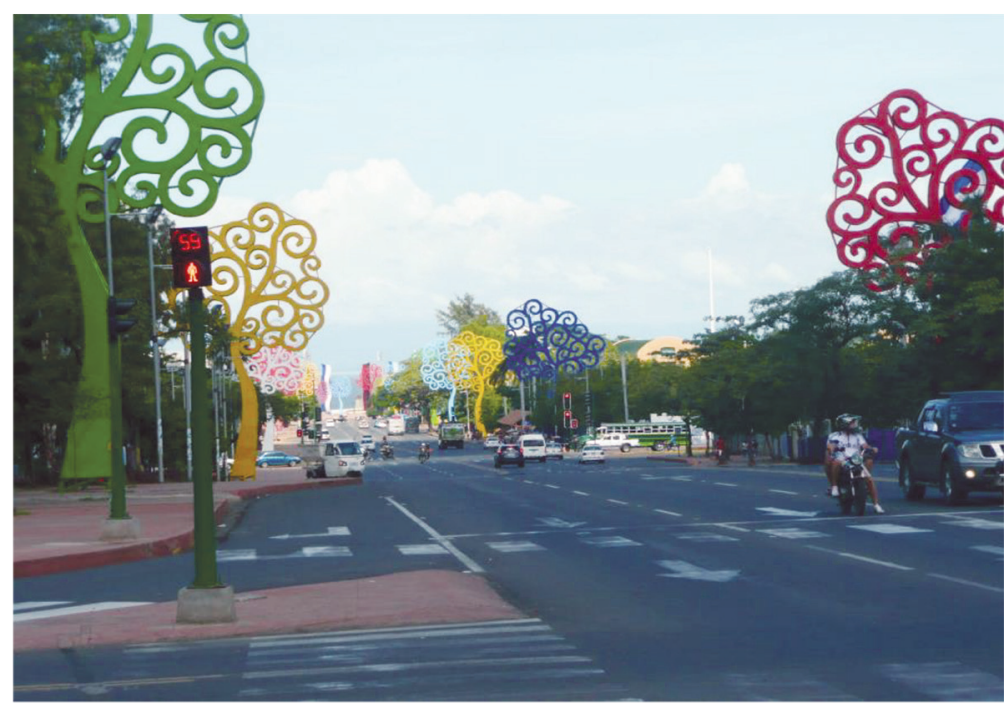

Fuente: Elaboración propia. 
Existen dos grupos principales que amenazan el control de Daniel sobre el poder: primero, los disidentes sandinistas urbanos, personas bien educadas que lucharon en la Revolución; y segundo, las poblaciones indígenas y afrodescendientes, los llamados Costeños, que habitan la Costa Caribe y tienen una larga historia de conflicto con los gobiernos de Managua (en general) y con el FSLN (en particular). Este artículo se centra particularmente en este último grupo, ya que se trata de personas que han estado luchando por la restitución de un conjunto de derechos históricos y se sienten cada vez más frustradas por los obstáculos políticos a la autonomía regional y al aseguramiento de los derechos a la tierra.

La estrategia de Ortega no es solo autoritaria, sino también agnotológica y colonial. Para Proctor y Schlebinger, la agnotología se refiere a la producción y reproducción de la ignorancia "a través de mecanismos como la negligencia deliberada o inadvertida, el secretismo y la supresión, la destrucción de documentos" (vii). Además, la colonialidad magnifica la agnotología. Como recuerda Mignolo, una de las principales consecuencias de la colonialidad en América "Latina" ha sido la supresión deliberada de conocimientos negros e indígenas, a través de la retórica de la modernidad. De Sousa Santos se refiere a una "sociología de las ausencias", cuya función se parece a la de la agnotología, en el sentido de que revela cómo las formaciones sociales hegemónicas intentan "destruir la experiencia social no hegemónica y potencialmente la contrahegemónica" (238). Por lo tanto, la sociología de las ausencias:

Trata de una investigación que intenta demostrar lo que no existe es en verdad, activamente producido como no existente, esto es, como una alternativa no creíble a lo que existe. El objetivo de la sociología de las ausencias es transformar objetos imposibles en objetos posibles, objetos ausentes en objetos presentes (238).

Por su parte, en la era contemporánea, el multiculturalismo oficial, expresado a través de la celebración de la diversidad étnica por la clase política latinoamericana, se convierte para Rivera Cusicanqui (99) en "el mecanismo de ocultación por excelencia para nuevas formas de colonización". El multiculturalismo oficial, como demuestra Juliet Hooker, es una herramienta utilizada por los Estados mestizos para aumentar su legitimidad, mientras neutralizan las demandas más radicales de los grupos racializados. Aunque el autoritarismo creciente del gobierno de Daniel Ortega es ampliamente reconocido (por ejemplo, Carroll 2008; Feinberg 2011; Smith 2011; Leyden-Sussler 2014), las estrategias del bloque de poder nicaragüense tienen dimensiones raciales que no se han analizado debidamente.

Se trabajó con medios radiales teledifusores indígenas y afrodescendientes en la Costa Caribe de Nicaragua. Asimismo, se ha analizado tanto la producción como el consumo mediático y se considera que las características coyunturales claves que rodean la movilización del movimiento social y su uso de los medios tienen 
implicaciones importantes para el ejercicio del poder hegemónico. Este estudio explora estas dinámicas a través de diversas formas de activismo mediático que tienen lugar en una Nicaragua cada vez más autoritaria.

\section{Movimientos sociales decoloniales, los gobiernos de izquierda y los medios}

Como es bien sabido, los fracasos del neoliberalismo en Latinoamérica dieron lugar a muchísima movilización social y política y a la elección de varios gobiernos en plataformas explícitamente antineoliberales. No obstante, es importante reconocer que los gobiernos latinoamericanos de izquierda o de la llamada marea rosa no son tan progresistas ni tan democráticos como parecen ser desde afuera. Como escribieron Madrid et al. (146), "en un esfuerzo por fortalecer su poder, han reescrito la constitución para permitir su propia reelección, han disuelto o manipulado las asambleas y han llenado las instituciones del estado con sus partidarios". Hablando de movimientos sociales en este contexto, Zibechi ha observado dos tendencias contradictorias. Por un lado, los gobiernos de marea rosa han tendido a neutralizar los efectos antisistémicos de los movimientos sociales y, por lo tanto, han contribuido a su fragmentación y desmovilización. Por otro lado, las modalidades de poder desplegadas por los movimientos sociales están empezando a cambiar de manera importante. Según Zibechi, hay grupos sociales que ya no se pueden controlar a través de la represión.

En consecuencia, las formas de poder vertical y molar que ejercen los agentes estatales interactúan con formas de poder horizontales, espontáneas, inmanentes, dispersas y moleculares que ejercen los movimientos sociales. En estas condiciones, el bloque de poder debe intentar "domesticar" o "reorientar" los movimientos sociales "para que beneficien a la clase dominante", pero la "dispersión organizativa" de estos movimientos es "mucho más potente que la del estado centralizado", y permite a los grupos sociales crear y defender sus propios espacios autónomos (Zibechi 309). Además, estos movimientos se nutren de los conocimientos negros, indígenas y descoloniales, de manera que contribuyen a la creciente crisis epistemológica que aflige la racionalidad eurocéntrica (Quijano), es decir, se reconoce que la modernidad eurocéntrica es incapaz de resolver los problemas que ha creado (de Sousa Santos).

Es un error pensar que existen sociedades latinoamericanas singulares que se componen de grupos sociales desfavorecidos, los cuales reclaman al Estado una reparación política (Zibechi). En cambio, hay dos sociedades asimétricamente opuestas, "una sociedad oficial, hegemónica y de origen colonial" (Zibechi 318) y otra basada en la cosmovisión indígena, los modos indígenas de gobierno y justicia y relaciones comunitarias no capitalistas en los cuales "el pasado -y no un futuro modernista- fomenta la acción" (Zibechi 328). En Nicaragua, la interacción entre estas dos modalidades de poder está produciendo una crisis coyuntural en el Estado mestizo vertical y le cuesta a este Estado cada vez más alcanzar la hegemonía por consentimiento, por 
lo tanto, debe recurrir a estrategias alternativas y agnotológicas, lo cual incluye el uso desenfrenado de la represión y la violencia dirigidas por el Estado.

Estos cambios en las formas organizativas de los movimientos sociales se producen paralelamente con los cambios en el entorno mediático; además, los cambios tecnológicos posibilitan estos cambios político-organizativos. Estamos presenciando interrupciones en los sistemas de medios centralizados, la aparición de nuevas plataformas tecnológicas, nuevas interacciones entre los medios "viejos" y "nuevos" y el movimiento rápido de textos y contenido a través de géneros y plataformas. Los procesos negativos, tales como la preocupante concentración de las compañías de medios y el aumento en la vigilancia digital, van acompañados de una democratización del acceso a los medios, lo cual le permite a los ciudadanos de base producir sus propios medios de comunicación e interactuar con los medios comerciales en formas que pueden ser políticamente transformadoras (por ejemplo, Jenkins 2006; Martín-Barbero 2011; Jenkins et al. 2013; Cupples y Glynn 2013, 2014; Castells 2012). Como observa MartínBarbero, las nuevas tecnologías "están siendo crecientemente apropiadas por grupos de los sectores subalternos posibilitándoles una verdadera 'revancha sociocultural', esto es, la construcción de una contrahegemonía a lo largo y ancho del mundo" (42). Por lo tanto, las demandas por los derechos humanos y la ciudadanía de las poblaciones indígenas y afrodescendientes circulan cada vez más en espacios mediáticos y en lo que Manuel Castells llama "redes horizontales de comunicación interactiva" (2007 246).

\section{La autonomía de la Costa Caribe Nicaragüense}

La Costa Caribe, tierra de los pueblos indígenas (Miskito, Mayangna y Rama) y Creole (afrodescendientes), nunca fue colonizada por España, pero fue violentamente anexada por Nicaragua en 1894, proceso que generó una lucha fuerte por la autodeterminación contra una cultura mestiza bastante hostil. En Nicaragua, como en otras partes de Latinoamérica, la ideología del mestizaje ha tendido a percibir a los indígenas y afrodescendientes como obstáculos para el desarrollo y la construcción de la nación, lo cual da lugar a una endofobia (desprecio o rechazo a lo propio) generalizada, al abandono social y económico de la región y a la idea de que las comunidades negras e indígenas representan un obstáculo al desarrollo y a la construcción de la nación (Duncan 2012; Hooker 2005b).

Estas actitudes se materializaron en la guerra de la Contra en la década de 1980, cuando 42 comunidades miskitas fueron sujetas al desplazamiento forzado por el ejército sandinista. Actualmente, las relaciones entre el Pacífico y el Caribe se caracterizan por distintas formas de colonialismo interno, el cual incluye los racismos institucionales y sociales, el abandono social, económico e infraestructural, la destrucción ambiental, el imperialismo cultural, el paternalismo y la folklorización. Hoy en día, los niveles de pobreza en la Costa Caribe siguen siendo mucho más altos que en el Pacífico 
y hay una destrucción ambiental generalizada causada por la sobreexplotación de los recursos marinos, madereros y minerales de la región (Silva).

Aunado a lo anterior, durante las últimas dos décadas, los costeños han tenido que soportar intensas presiones migratorias del Pacífico, proceso que los mismos costeños denominan "invasión del Pacífico". Los agricultores mestizos del Pacífico, conocidos como colonos o terceros, se han asentado en tierras comunales y se dedican a diversos modos de subsistencia agrícola, ganadería y deforestación, lo cual ocasiona muchos conflictos con los habitantes indígenas y muchísima destrucción ambiental.

La resistencia de los costeños a lo que se puede llamar el colonialismo interno, junto con la existencia de un clima político internacional que se ha vuelto mucho más favorable a la reparación poscolonial de los pueblos indígenas, significan que se han abierto varios espacios para la reivindicación de los derechos políticos de los pueblos indígenas y afrodescendientes. Los derechos de los nicaragüenses indígenas y afrodescendientes a la autonomía fueron reconocidos en la Constitución nicaragüense de 1987. Las luchas políticas y militares de los años ochenta culminaron en la aprobación de una ambiciosa Ley de Autonomía (Ley N. ${ }^{\circ}$ 28) en 1987; no obstante, tardaron 16 años en ratificarla.

Así las cosas, la Ley se ratifica dos años después de un histórico caso legal en el cual la Corte Interamericana de Derechos Humanos dictaminó en contra del Estado nicaragüense en el caso de la comunidad Mayangna Awas Tingni y confirmó el derecho de esta comunidad a la propiedad comunal frente a las concesiones madereras (Grossman 2001). En 2003, la Asamblea Nacional aprobó la Ley N. ${ }^{\circ} 445$, conocida como Ley del Régimen de Propiedad Comunal de los Pueblos Indígenas y Comunidades Étnicas de las Regiones Autónomas de la Costa Atlántica y de los Ríos, Bocay, Coco, Indio y Maíz. Esta Ley trata de la propiedad comunal y la gestión de los recursos naturales. Nicaragua también ha apoyado iniciativas mundiales a favor de los derechos indígenas, al votar a favor de la Declaración de Derechos Indígenas de las Naciones Unidas en 2007 y ratificando el Convenio 169 de la OIT en 2010.

La Ley N. ${ }^{\circ} 445$ se compone de cinco etapas (solicitud, resolución de conflictos, demarcación, titulación y saneamiento) y debería haberse completado en el año 2010 (Antonio 2008). El proceso ha sido muy lento, en parte debido a la falta de apoyo del gobierno central, al intervencionismo nocivo de los partidos políticos del Pacífico, a la inexperiencia legal de los líderes costeños, y a la incompatibilidad entre el sistema de gobierno eurocéntrico y el indígena. Las primeras cuatro fases se han completado en 22 de 23 comunidades. La quinta etapa, el saneamiento, se refiere específicamente a la presencia de colonos o terceros que residen ilegalmente en tierras comunales tituladas y no se ha completado en ninguna parte.

La posición oficial sandinista sobre la autonomía es que es "un proyecto histórico con el que el Gobierno de Reconciliación y Unidad Nacional está profundamente comprometido" (Mairena 7), pero el gobierno trata de contener el discurso pro autonomía 
dentro de un marco nacionalista y sandinista y margina los elementos más radicales que frecuentemente movilizan los miskitos y los Creoles.

También demuestran una falta de respeto hacia los modelos indígenas de gobierno. Varios presidentes territoriales democráticamente elegidos conforme con la ley de autonomía han sido sacados del poder por el Gobierno Regional sin ninguna consulta con los comunitarios. El gobierno aprobó la ley del canal interoceánico (Ley N. ${ }^{\circ} 840$ ) sin llevar a cabo la consulta legalmente obligatoria con las comunidades Creoles e indígenas que viven en su camino.

\section{Los espacios mediáticos en Nicaragua}

Es ampliamente reconocido que la existencia de medios libres, independientes y críticos que son capaces de responsabilizar a quienes están en el poder es fundamental para la democracia (Rothschuh Villanueva). Sin embargo, en Nicaragua la familia Ortega-Murillo ha tomado medidas extremas para socavar la libertad de prensa. Estas medidas incluyen la compra y la cooptación de periódicos y canales de radio y televisión y la centralización y difusión vertical de las comunicaciones oficiales del gobierno a través del Consejo de Comunicación y Ciudadanía liderado por la primera dama y ahora vicepresidente Rosario Murillo. Diariamente, a través de la televisión, radio e internet oficialistas, Murillo le cuenta al país lo maravilloso que es todo, haciendo hincapié en la paz, la prosperidad y el empleo.

Esta estrategia vertical se acompaña de lo que Olivares llama un "apagón informativo", ya que el gobierno casi ha dejado de recopilar y publicar estadísticas gubernamentales e indicadores de desarrollo. La información oficial necesaria ha sido reemplazada por información oficialista destinada a desviar la atención de los problemas de Nicaragua. Además, el presidente nunca da entrevistas o celebra conferencias de prensa y se prohíbe a los ministros y empleados del gobierno hablar con los medios y corren el riesgo de perder el trabajo si lo hacen.

Los medios independientes han sido sometidos a auditorías pesadas, su equipo ha sido destruido o sus vehículos han sido dañados. Cuando ocurren cosas importantes, muchas veces la policía impide el paso a los periodistas independientes. Algunos periodistas también han recibido amenazas de muerte enviadas a sus teléfonos celulares o han sido atacados físicamente en espacios públicos mientras hacen su trabajo por los grupos de choque, o sea, delincuentes reclutados por el Gobierno para crear problemas (Orozco y López; La Prensa 2015a, 2015b; Cenidh Nicaragua 2015).

La televisión nicaragüense está en gran parte en manos de un duopolio, lo cual según Carballo et al. (2014) viola Artículo 68 de la Constitución. La familia Ortega-Murillo posee los canales 4, 6, 8 y 13, mientras que el empresario mexicano Ángel González controla los canales 2, 9, 10 y 11. Entre los dos controlan el 90 por ciento de los canales de televisión de libre acceso y más de 100 emisoras de radio. Ahora solo 
hay un canal de televisión nacional libre, Canal 12, y tres canales nacionales de cable, 14, 15 y 23, que no pertenecen al duopolio. Hay una reducción parecida en la circulación de periódicos independientes. Como escriben Orozco y López, "se ha instalado en Nicaragua una dictadura oficial mediática que intenta demostrar que el país, sus instituciones y su población están bien" (174).

Los mismos problemas se repiten a escala local. La coyuntura actual afecta de manera negativa a los medios comunitarios de la Costa del Caribe que desempeñan un papel importante en el proceso de autonomía y en la lucha contra representaciones racistas que dominan en los medios de comunicación nacionales. Hasta ahora, muchas emisoras locales se han financiado gracias a la publicidad estatal, al transmitir, por ejemplo, anuncios del Ministerio de Salud, pero el Gobierno ha ido eliminado esta publicidad de las emisoras críticas e independientes. La eliminación partidaria de la publicidad estatal pone a muchas emisoras costeñas en una posición económica precaria y afecta su capacidad de utilizar sus medios de comunicación para luchar por los derechos culturales y políticos. De hecho, alienta a algunos de ellos, como nos dijo la dueña de un canal de radio Creole, a concentrarse en el béisbol y la música y evitar tocar temas políticos. Además, los sandinistas también han financiado estaciones locales de radio (Bilwi Stereo, Bluefields Stereo) y televisión (Canal 22) rivales en un intento de reducir el público de los medios comunitarios.

El bloque de poder sandinista hace esfuerzos enormes para intentar silenciar a los medios comunitarios. Por ejemplo, para fortalecer la participación comunitaria en el proceso de demarcación, el gobierno Creole de Bluefields comenzó a alquilar un espacio en Radio Rhythm para emitir un programa semanal de historia negra Creole que se llamaba Demarcation Now. Fueron sacados del aire debido a presión política sobre el dueño. Estos intentos de silenciar a los medios demuestran como la circulación de las historias negras desafía los modos de colonialidad que engendran las ideologías mestizas. Produce entendimientos alternativos del Estado nación nicaragüense, no como una fuente de orgullo, sino como resultado de una anexión violenta que llevó a la supresión cultural de los conocimientos negros e indígenas. También desafía los entendimientos geopolíticos eurocéntricos dominantes que ven a los costeños indígenas y negros como "personas sin historia" (Mignolo xii). Estos imaginarios son producto de la "ignorancia blanca", la cual según Mills (2015) constituye "un tipo de epistemología" y un "tipo de no conocimiento útil" que exige "siempre una comprensión vigilante de lo que no se debe saber" (Gross y McGoey 5).

Cuando las operaciones de los medios comunitarios son amenazadas, los oyentes a menudo se movilizan para defenderlos. Por ejemplo, después del Huracán Félix, el bloque de poder sandinista trató de evitar que una emisora de radio Miskita discutiera la distribución corrupta de ayuda cortando su suministro de energía, pero la comunidad llegó para evitar que esto sucediera. 
Pero la situación es verdaderamente grave. Un locutor de televisión ${ }^{3}$ nos contó cómo había recibido llamadas y mensajes amenazantes durante la transmisión de un programa que cubría las opiniones de personas que viven en el camino del canal interoceánico.

El documental no había terminado, cuando ya me estaban llamando y mandando algunos mensajes de personas que estaban viendo el documental que son parte del gobierno, porque el documental básicamente era de personas en contra del canal y en cierta forma me tocó pedir disculpas por temor a que mi medio sea cerrado. Y yo vivo de esto, este es mi trabajo, con esto yo le doy trabajo a ellos dos, con esto yo cuido de mi familia, entonces si yo como medio de comunicación tengo este temor, ¿Qué temor tiene la población?

Algunos periodistas costeños también han recibido amenazas de muerte. El 30 de octubre de 2015, el locutor miskito Juan Herbacio fue agredido físicamente por una multitud sandinista que lo asaltó mientras hacía compras en el supermercado (La Prensa, 2015b). Los mensajes también amenazaron con quemar su emisora. ${ }^{4}$ En agosto de 2015, en el Día Internacional del Periodista, el reportero miskito, Jerry López, produjo un corto documental emitido en TV7, en el cual los periodistas y comunicadores describen el clima de intimidación y autocensura en el cual son obligados de operar (Joel EMC 2016).

La producción de los medios indígenas se ha convertido en una actividad peligrosa, no hay duda de que la estrategia mediática del bloque de poder sandinista es devastadora para la libertad de prensa en Nicaragua y constituye una violenta forma de aniquilación simbólica. Lo que la estrategia no reconoce es que en las palabras de Castells (244) "los medios son el espacio donde el poder se produce, no donde el poder se sostiene". Los intentos de ignorar, reprimir y silenciar solo tienen éxito parcial, ya que los actores sociales recurren a otros métodos y espacios mediáticos que están más allá del alcance del FSLN.

\section{Crisis y conflicto en la Costa Caribe}

Después de 2008, el proceso de demarcación se iba acelerando en la Costa Caribe Norte, pero los colonos continuaban migrando desde el Pacífico hasta la Costa donde desplazaron los bosques, vendieron ilegalmente la madera valiosa, trajeron ganado, construyeron casas y se dedicaron al tráfico de tierras ilegal apoyado por documentos falsificados. Desde 2010, el gobierno ha recibido notificación de 339 casos de invasiones y titulación ilegal de propiedad comunal indígena en la región de Bosawas. Estos casos han sido meticulosamente documentados y mapeados por los gobiernos territoriales y presentados a la policía. A pesar de las intervenciones de los diputados de la Asamblea Nacional que instan tanto al jefe de policía nacional como al presidente a seguir los casos, no se ha hecho absolutamente nada (Navas). 
La destrucción ambiental creada por los colonos ha sido colosal. En 1997, el bosque de Bosawas, el cual es una Reserva de la Biosfera de la Unesco, tenía más de 2 millones de hectáreas de bosques protegidos y allí vivían 7000 habitantes indígenas. Para el 2013, la población había aumentado a 40000 y el bosque se había reducido a 832 237 hectáreas (Silva).

A mediados de 2015, la situación se había empeorado, especialmente en las comunidades alrededor de Waspam en el Caribe Norte. Los colonos ahora están bien armados, se han vuelto mucho más violentos y han comenzado a destruir las casas y los cultivos de los comunitarios y no les dejan llegar a sus campos y a sus cultivos. Muchos de ellos tienen armamento de grado militar, lo que provoca la sospecha de que estén siendo suministrados por el ejército. Algunos miskitos también han tomado las armas para defenderse y tomar represalias. Debido al hambre y la falta de seguridad centenares de miskitos han sido desplazados a la capital regional, Bilwi, o a Honduras. Para septiembre de 2015, 800 familias habían sido desplazadas, 60 casas habían sido destruidas, y 15 personas habían sido asesinadas y muchas más han resultado heridas (Silva). A pesar de todo eso, las fuerzas de seguridad nicaragüenses han estado ausentes y han actuado en contra de los dueños legales de las tierras en vez de en contra de los colonos. En septiembre de 2015, tres líderes miskitos resultaron gravemente heridos en una emboscada del ejército mientras intentaban entregar comida y ayuda humanitaria a las familias bajo asedio como resultado de la violencia de los colonos (Chamorro). Poco después de denunciar estos abusos de derechos humanos, uno de estos líderes fue acusado por el FSLN de participar en la venta ilegal de bienes comunales. El 17 de diciembre de 2015, un grupo de colonos atacó las comunidades de Wisconsin y Esperanza, lo cual resultó en tres muertes, tres personas heridas y tres secuestros (Romero). Los medios independientes comenzaron a publicar titulares como "Hambre y abandono en comunidades RAAN" (Navarro) y "El gobierno niega crisis indígena ante la $\mathrm{CIDH}$ [Comisión Interamericana de Derechos Humanos]" (Romero et al. 2015), capturando tanto la violencia y el sufrimiento en las comunidades como la producción deliberada de la no existencia indígena y negra por el bloque de poder sandinista.

El concepto de la sociología de las ausencias (de Sousa Santos) sirve para comprender cómo los Costeños desafían los intentos del bloque de poder sandinista de cerrar alternativas contra-hegemónicas y restringir lo que existe. De Sousa Santos afirma que las fuerzas hegemónicas producen activamente la no existencia a través del privilegio de cinco monoculturas: conocimiento (científico/eurocéntrico), tiempo (lineal), clasificación (racial), escala (global/universal) y productividad (capitalista y de mercado). Pero estas monoculturas pueden ser reemplazadas por ecologías que hacen visibles los conocimientos, las temporalidades y los sistemas económicos alternativos, que reemplazan las jerarquías con el reconocimiento y que invierten las lógicas escalares de la globalización. Los intentos del bloque de poder sandinista 
de establecer un monopolio sobre la credibilidad se ven frustrados por los discursos opositores de los grupos costeños que hablan sobre los derechos territoriales, las identidades culturales, los recursos naturales y los megaproyectos neoliberales. Por consiguiente, surge una contrahegemonía ecológica (parcial, fragmentada e híbrida) que sienta las bases para lo que Sousa Santos describe como una sociología de las emergencias. Esto se hace posible no solo por la dispersión del poder, sino también por las formas de conectividad afectiva facilitadas por la interacción mediática.

Dada la urgencia de la situación, los líderes territoriales y comunales y los defensores de los derechos humanos están ansiosos por completar el proceso de demarcación. La Ley N. ${ }^{\circ} 445$ no especificó cómo se llevaría a cabo la etapa final (saneamiento), entonces pedían a las autoridades de Managua que entraran en negociaciones con ellos para acordar el proceso. Estos intentos fueron recibidos con total silencio por parte del bloque de poder sandinista. Frente a este silencio, CEJUDCHAN y los líderes comunitarios elaboraron un manual que recomendaba un proceso viable y viajaron a Managua para presentar su propuesta a las autoridades.

No obstante, debido a la falta de respuesta hasta entonces, decidieron filmar esta fase de su lucha. El resultado es una película titulada "Documental CEJUDHCAN", disponible en YouTube, que captura la situación en que se encuentran (Cejudhcan derechos humanos 2015a). Los presidentes de los 23 territorios negros e indígenas y sus simpatizantes hicieron el arduo viaje en bus desde Managua con la intención de reunirse con las autoridades en el Crowne Plaza, un hotel céntrico de Managua. El video explica lo que es la Ley 445 y la gravedad de la situación actual. También muestra cómo su intento de entablar un diálogo horizontal e interepistémico con el bloque de poder sandinista fracasó al no aparecer ninguno de los invitados. Lo hace filmando las sillas vacías (Figura 3) que llevan los nombres de los oficiales invitados. En el lugar de los funcionarios ausentes, el video contiene una explicación de la Ley N. ${ }^{\circ} 45$ y de la obligación legal del Estado a trabajar para cumplir el proceso de saneamiento. Los participantes le cuentan a la cámara la urgencia de la situación, las amenazas a sus formas de vida y la grave destrucción ambiental que se produce a través de la presencia cada vez más intensa de terceros en sus territorios. El video revela que Nicaragua no es un país democrático en el que la autonomía está floreciendo, sino más bien uno en que los derechos negros e indígenas, e incluso los intentos de diálogo, son denegados. 


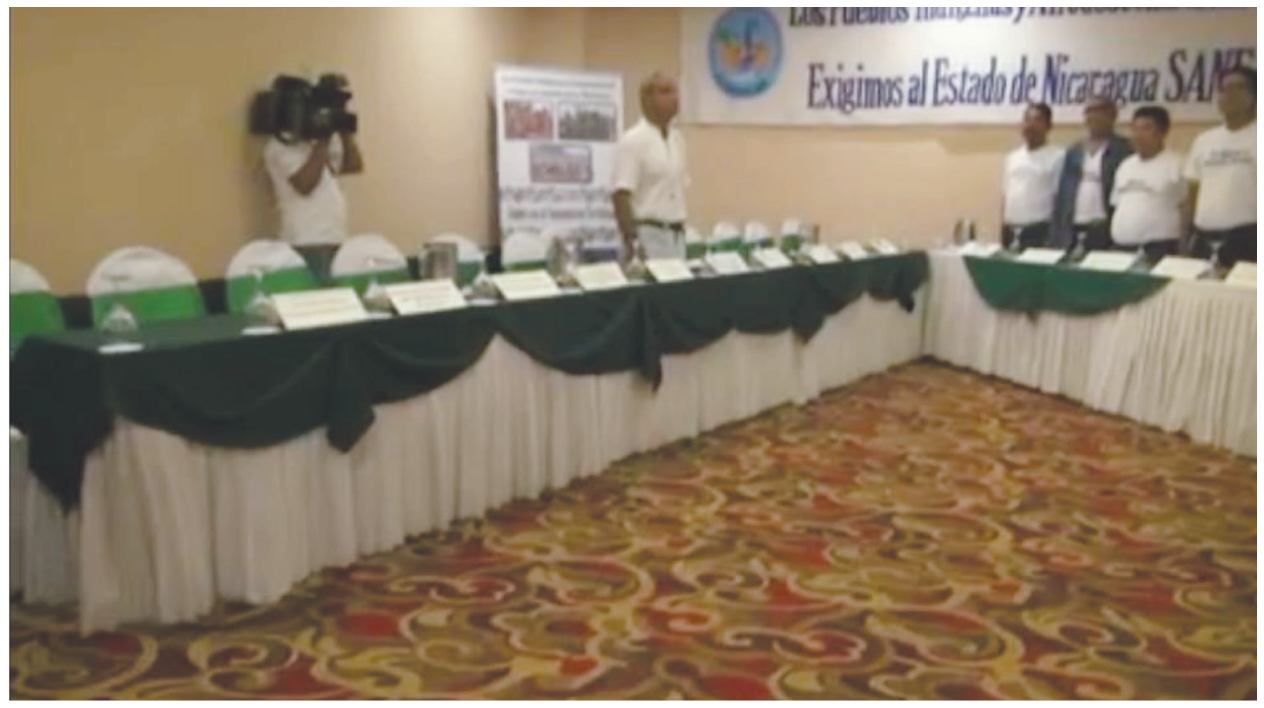

Fuente: CEJUDHCAN, derechos humanos (2015a).

Como anota Adams, en un artículo sobre la silla vacía del preso político chino Liu Xiaobo en la ceremonia del Premio Nobel de la Paz de Noruega en 2010, las sillas vacías pueden producir dos modos de comunicación, contenidos y contextos, simultáneamente. Al igual que el Ayuntamiento de Oslo, discutido por Adams, el Crowne Plaza de Managua sirvió "como un contenedor lleno de testigos a una ausencia muy particular" (315), en el que los cuerpos ausentes que no desean comunicar nada terminan comunicando mucho sobre sus actitudes hacia la autonomía de la Costa Caribe. Así que el Crowne Plaza como contenedor no tiene fronteras claramente definidas y es capaz de conectarse con otros lugares. Además, hay ciertas representaciones que se codifican en la comunicación. Como escribe John Fiske (230), "el hacer visible... es una forma de contrapoder, y el conocimiento que produce y circula funciona para construir y validar una contra realidad".

Ahora el CEJUDHCAN ha completado varias películas más que intentan acabar con la agnotología sandinista. Una tiene subtítulos en inglés en un intento de asegurar la solidaridad global (CEJUDHCAN, derechos humanos 2015b). También filmaron un viaje de campo emprendido por habitantes del territorio Wangki Twi Tasba Raya para verificar el número de terceros presentes en su territorio y la extensión de la destrucción de recursos naturales (CEJUDHCAN, derechos humanos 2015c). El video documenta el despale masivo de grandes franjas de bosque, la presencia de ganado 
y la contaminación de los ríos (Figura 4). Como señala uno de sus técnicos, es obvio que el trabajo no se hizo con machetes y hachas, sino con motosierras, lo que indica que los colonos no son campesinos empobrecidos o, si lo son, cuentan con maquinaria costosa suministrada de otras personas. Durante la filmación se encontraron con un colono que les dijo que había comprado 100 manzanas (70 hectáreas) de tierra por C\$ 300000 (alrededor de USD 10 000) y que ya había despalado completamente unas 45 manzanas. Así que los miembros de la comunidad documentaron el comercio ilegal de sus tierras junto con la destrucción ambiental.

Figura 4

\section{DESTRUCCIÓN AMBIENTAL EN WASPAM}

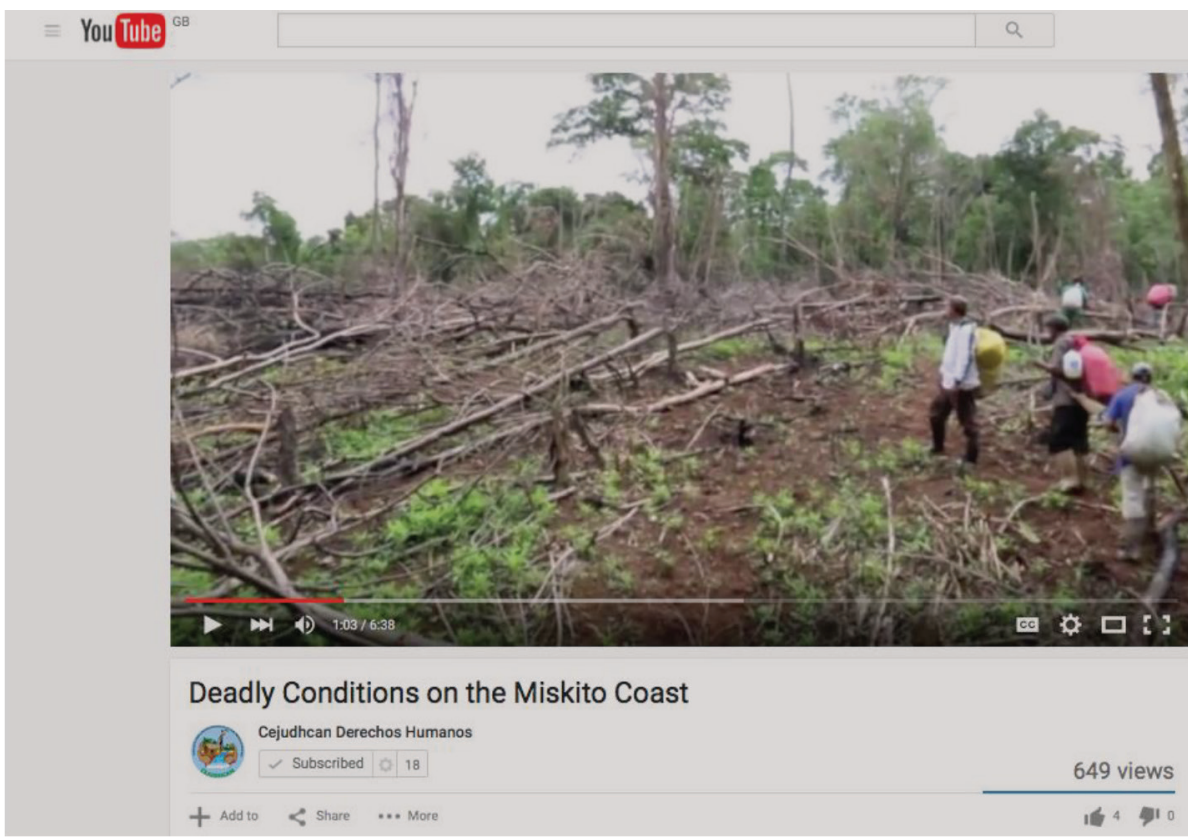

Fuente: CEJUDHCAN, derechos humanos (2015c).

Inspirado quizás por la nueva visibilidad mediática que CEJUDHCAN ha traído al conflicto, un grupo de jóvenes miskitos de la comunidad de Francia Sirpi escribió, interpretó y filmó una canción sobre "la invasión territorial de los colonos" y su lucha por la justicia (CEJUDHCAN derechos humanos 2015d) (Figura 5). Estos intérpretes se muestran reunidos en sus tierras ancestrales donde cantan sobre los "muchos problemas y situaciones" que afligieron a Francia Sirpi en 2015, lo cual incluye la incapacidad de cultivar o cruzar el río con seguridad, la desaparición de la vida silvestre y la deforestación generalizada de los árboles de cedro y caoba. Su canción describe un encuentro con 
un colono que huye a las montañas con miedo cuando lo enfrentan, y pide a las "autoridades" que "nos apoyen, nos apoyen". La canción se apropia del lenguaje y el imaginario del pasado revolucionario de Nicaragua preguntando "Comandante: hombre valiente, ¿dónde estás?". De esta manera, los cantantes se apropian de los significados de la revolución nicaragüense de forma subversiva para avanzar sus propias luchas por los derechos territoriales indígenas contra una invasión colonial ilegal. Cuando llaman “¿dónde estás?", estos cantantes miskitos reclaman al Estado mestizo por no implementar la ley y mantener la seguridad, y subvierten la norma mestiza contra la cual la identidad indígena es marcada repetidamente como otra. Las representaciones del video están codificadas en lo que John Fiske (138) llama el modo "videolow" de la grabación de un teléfono celular: una "baja tecnología" que es "baja en claridad pero alta en autenticidad", porque se deriva de "la relación aparentemente continua o metonímica del "videolow" con las verdades experienciales (o experiencias 'verdaderas') de los socialmente marginados".

Figura 5

LOS JÓVENES DE FRANCIA SIRPI

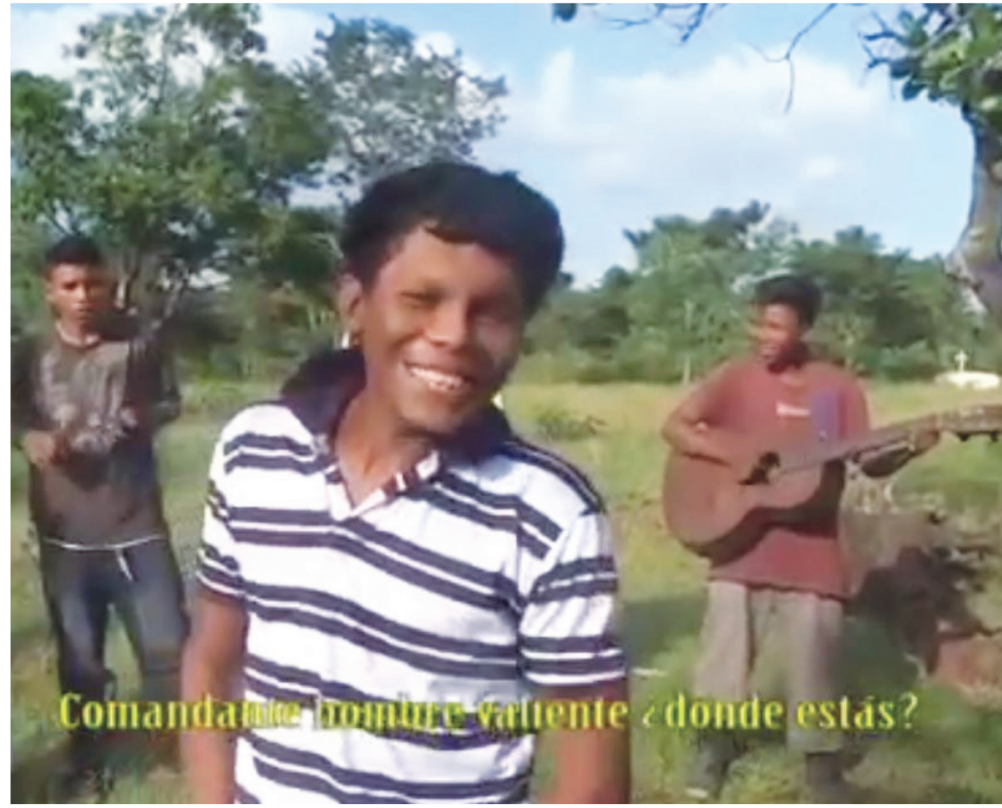

Fuente: CEJUDHCAN, derechos humanos (2015d).

Otros Costeños también han estado subiendo material sobre los conflictos recientes a YouTube. El contenido mediático se está moviendo de los medios comunitarios locales a YouTube, aumentando su circulación y el potencial que tiene de ser 
remediatizado. Por ejemplo, Saúl Fúnez tiene un canal de YouTube al que sube los informes noticieros sobre los conflictos que se transmiten en TV7, un canal de televisión comunitario de Bilwi. A diferencia de los informes de los principales medios de comunicación, estos informes son recopilados por comunicadores y periodistas indígenas y Creoles. Proporcionan más contexto, dan voz amplia a los miembros de la comunidad afectada y hacen informes sustentados en la cosmovisión indígena. Además, practican una incidencia proindígena en el sentido de que defienden abiertamente a los derechos indígenas. Lo que vemos son mujeres y hombres indígenas luchando por los derechos territoriales con niveles altos de alfabetización legal.

En un informe titulado "Conflicto entre miskitos y colonos" (Funez) (Figura 5), el reportero dice:

Los miskitos están cansados de ser pisoteados por los colonos en su propia casa y están dispuestos a dar sus vidas por la Madre Tierra. Las leyes están claras, estas tierras no pueden ser confiscadas, vendidas o transferidas. Sin embargo, hay personas corruptas que se ocupan de estas transacciones y se están enriqueciendo, cuyas consecuencias deben pagarse.

La cámara se mueve a una mujer de la comunidad que se ve triste y enojada y le dice al reportero:

Estamos dispuestos a morir defendiendo nuestras tierras, llegaron a invadirnos, y no nos dejan ir a trabajar, han matado a todos los animales salvajes. Ahora mismo no hay paz para la Costa Atlántica. La Costa Atlántica se ha convertido en un desastre.

Luego, entrevistan a un hombre de la comunidad a que se refiere a los derechos legales que ahora poseen los miskitos diciendo "Crearon los territorios y ahora estos territorios tienen sus propias leyes de acuerdo con la Ley 445, la Ley 28 y la Constitución política de Nicaragua". Un segundo hombre en uniforme militar frente a un grupo de miskitos armados le dice al reportero que son ocho comunidades que están ahora involucradas en el entrenamiento militar para defender sus tierras. La voz vuelve al reportero que hace una dirección directa a la negación sandinista.

Corresponde al gobierno proporcionar seguridad a sus ciudadanos. Sin embargo, todas las autoridades están haciendo la vista gorda y por lo tanto el conflicto entre miskitos y colonos continúa en las montañas dentro del territorio de Wangki. Por lo tanto, la presencia inmediata de la policía y del ejército es urgente para evitar más derramamiento de sangre.

El clip termina enseñando una panga llena de miskitos armados que viajan por el Río Coco para enfrentarse a los colonos, obligados a defenderse dada la ausencia de la seguridad estatal (Figura 6). 
Figura 6

PANGA EN EL RÍO COCO CON UN GRUPO DE MISKITOS ARMADOS

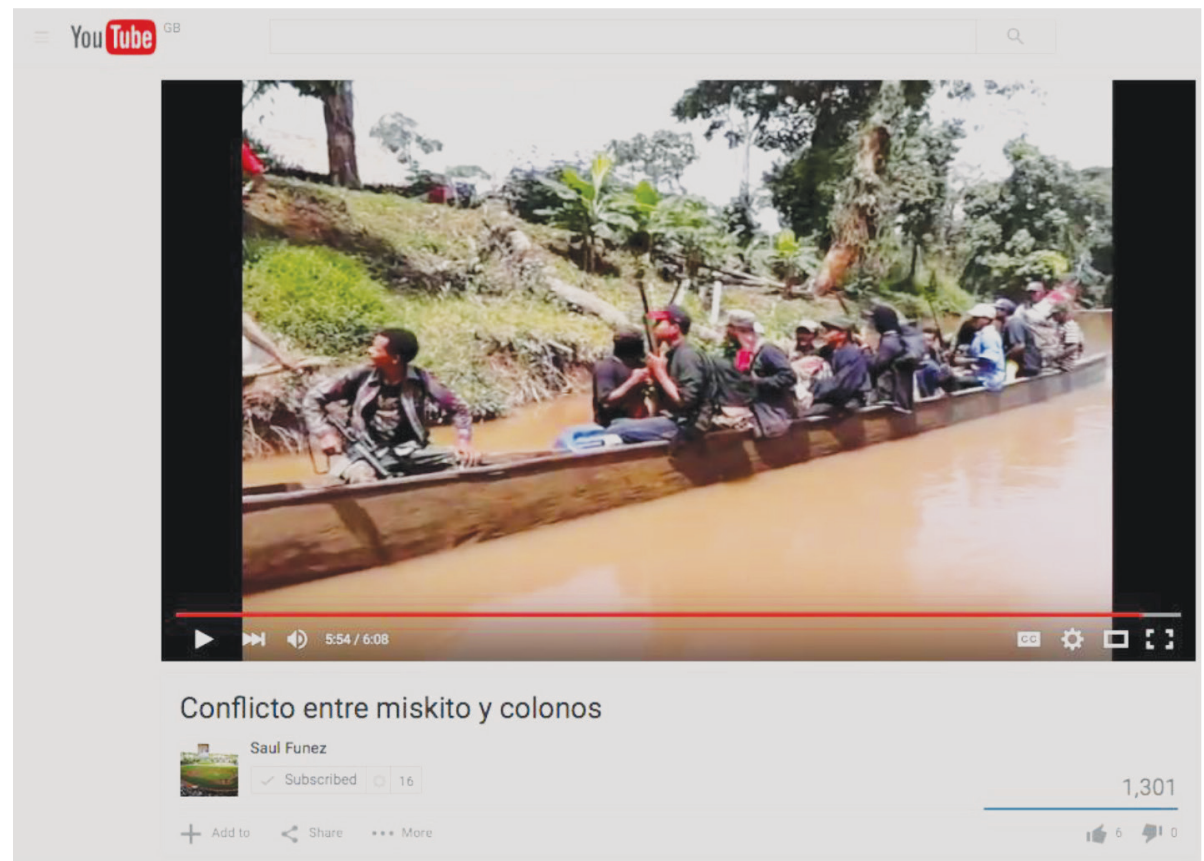

Fuente: Funez 2015.

La comunidad Rama Kriol de Bangkukuk Taik en el Caribe Sur se enfrenta a la destrucción inminente como resultado del canal interoceánico. Trabajando con una ONG nicaragüense, Centro de Asistencia Legal a Pueblos Indígenas (CALPI), los miembros de la comunidad han producido un documental, titulado "Bangkukuk Taik an indigenous Rama community and the Nicaraguan interoceanic grand canal", disponible en YouTube (Bangkukuk Taik) que contrasta la producción sandinista de ausencias con una sociología indígena de emergencias que revela las prácticas coloniales agnotológicas del Gobierno.

Por ejemplo, habla de una mentira oficial acerca de por qué se había colocado un mojón en su comunidad, de la falta de información y consulta sobre el canal, y de cómo el tipo de desarrollo que el canal promete no es compatible con la supervivencia de la cultura Rama Kriol. Entonces, los comunitarios responden a la cuestión del canal desde una epistemología alternativa, arraigada en una historia rica y en una economía autosuficiente que va más allá del Estado, en un rechazo anticapitalista del dinero y un sentido de responsabilidad hacia la tierra, el agua, la flora y la fauna. Es una cultura en la cual los ancianos transmiten las prácticas culturales y el lenguaje Rama a los niños, y en la cual el tiempo es no lineal, dado que la posteridad y el 
bienestar futuro de los Rama Kriol dependen de la conservación de los esfuerzos de sus antepasados. ${ }^{5}$

La película proyecta la belleza de la vida cotidiana, donde la comida es abundante, la cultura es vibrante, y los niños tienen mucha libertad para jugar. El sentido del lugar y la condición de bienestar son palpables. En respuesta a la idea de que el canal traerá desarrollo, el pastor de la comunidad, Roberto Wilson dice: "Así que les dije, no necesito dinero porque no vivimos por dinero. Vivimos por la tierra y el agua que Jesús nos dio en nuestro territorio y en nuestro país. No necesito dinero. Les digo que el dinero no es bueno".

La tesorera de la comunidad, Kathelin Alvarado, dice: "Aquí, no compramos nada, conseguimos pescado fresco, plantamos y comemos tranquilo, nadie nos molesta". El presidente comunal de la comunidad vecina de Monkey Point afirma que la Ley N. ${ }^{\circ}$ 840, que establece el derecho del gobierno sandinista de crear un canal interoceánico:

Se creó con un objetivo: hacer que el gobierno pudiera realizar el proyecto sin consultar a nadie de Nicaragua. Simplemente él toma la decisión y lo hace como quiere y hace lo que quiere en el territorio. Usar la tierra, la propiedad donde quiere usarla sin tener que consultar con nadie.

$\mathrm{Al}$ referirse al gobierno como si fuera una sola persona, indica la falta de confianza en la democracia nicaragüense y su posición crítica ante el caudillismo autoritario de Ortega. De forma parecida, el presidente comunal de Bangkukuk Taik, Carlos Bilis afirma que "no vivimos del gobierno, lamento decírselo, pero no vivimos del gobierno", y declara que el proyecto canalero tiene como objetivo convertir a la gente de su comunidad en "esclavos" de los mestizos, demostrando que lo entiende como un proyecto colonial. La confianza en su lucha descolonial también se expresa cuando Bilis dice: "tenemos la última palabra sobre el tema del canal porque la tierra pertenece al pueblo indígena". Ocupa entonces lo que Enrique Dussel describe como "el lugar de la afirmación" dentro de la cual puede tener lugar la negación en la negación del sistema" (cit. por Sáenz 214).

La lucha de los Rama Kriol para defender su comunidad, su cultura y su forma de vida no debería verse como una lucha antimoderna, ya que es una lucha multifrontal por una forma particular de modernidad indígena. De hecho, su comunidad persigue esta lucha y defiende sus derechos e intereses en varias escalas y en varios espacios: en la capital Managua, en las Naciones Unidas, en YouTube y en otras partes del internet, en sus interacciones con periodistas internacionales, y en sitios donde llevan a cabo investigaciones detalladas sobre la propuesta del canal y donde desarrollan el nivel de alfabetización legal necesario para defender la comunidad. No dejan duda de que el proyecto del canal, si va adelante, constituirá un epistemicidio junto con la destrucción de un ecosistema. La propuesta canalera se representa aquí como un proyecto hipermoderno incrustado en discursos de desarrollo modernistas que 
solo pueden mirar hacia delante y la película imagina una modernidad alternativa que lucha en contra de la modernidad hegemónica cuya realización depende de la producción continua de la colonialidad (Mignolo xv).

En mayo de 2016, ante la persistente oposición de Rama Kriol, el Gobierno desplegó una mezcla de cooptación y engaño para convencer a algunos de los líderes de la comunidad a firmar un documento que decía que aceptaban el uso de sus tierras para el canal. Los medios prosandinistas informaron que el acuerdo había llegado después de dos años y medio de amplias consultas, y que el proyecto estaba arraigado en el concepto indígena y profundamente anticapitalista de Buen Vivir.

Un artículo en un medio oficial afirma que el presidente de los Rama Kriol, Héctor Thomas Macrae, indicó que su gente cree que "el proyecto del canal contribuirá al Buen Vivir de las comunidades, generará bienestar, protegerá la cultura y respetará las tradiciones ancestrales y los sitios sagrados y arqueológicos que son patrimonio histórico heredado de los antepasados" (Prado Reyes). Al mismo tiempo, los medios independientes comenzaron a circular narrativas alternativas, donde algunos Rama Kriol denunciaron el acuerdo como ilegal (Rezaye Álvarez; Vílchez; Confidencial). Otros confirmaron en los medios sociales que no habían consentido al uso de sus tierras (Onda Local 2016a, 2016b y 2016c).

En julio de 2016, se publicó en Vimeo y en otras redes sociales un nuevo video de los Rama Kriol (Bangkukuk Taik 2016) que cuestionaba las afirmaciones de Thomas sobre el consentimiento comunal para el proyecto del canal. La película comienza con subtítulos que explican la importancia de la Ley N. 445 (que garantiza los derechos territoriales de Rama Creole) y la Ley N. 840 (que permite la construcción del canal), exhibida sobre imágenes de la vida cotidiana en las comunidades Rama Kriol. Luego, el video muestra un informe que fue transmitido por la televisión Sandinista en mayo de 2016 sobre el acuerdo "histórico" entre el Gobierno Territorial Rama-Kriol (GTRK) y la Comisión Nicaragüense del Gran Canal Interoceánico, según el cual el GTRK otorgó el consentimiento de las nueve comunidades de Rama Kriol para la construcción del canal. El resto del video pasa por varias comunidades y los habitantes confirmaron que nunca consintieron al acuerdo. Así, el video contradice fuertemente la narrativa circulada por la televisión Sandinista.

En comunidad tras comunidad, las personas se reúnen para declarar a las cámaras que no se les dio oportunidad de una consulta libre, previa e informada. Un líder de la comunidad explica que "el dinero nunca me engaña... En este momento, tenemos un poquito de pescado. Tenemos un poquito de langosta. Tenemos un poquito de tortuga. Tal vez tengamos un animal [por familia]. Tenemos un poco de tierra. Pero si ese proyecto viene aquí ahora, no tendremos nada. Vamos a perder todo". En Rama Cay, una mujer apasionada dice que "el dinero es temporáneo, pero nuestro territorio es para siempre. Tenemos que pensar, el dinero se gasta, pero el territorio siempre va a estar, y lo tenemos que defender." 
El rechazo de los Rama Kriol a la globalización neoliberal y neocolonial y al desarrollo ambiental y culturalmente destructivo, junto con su uso de plataformas de medios globales para afirmar sus derechos como Rama y como pueblos indígenas, y para conectarse con el derecho internacional y campañas de solidaridad global, puede ser entendido en términos de lo que de Sousa Santos $(2004,240)$ llama la "ecología de la trans-escala", que recupera los elementos de lo local que "no son el resultado de la globalización hegemónica" y que, por lo tanto, conduce hacia "la desglobalización de lo local y su eventual re-globalización contra-hegemónica”. El activismo mediático y visual de los Rama Kriol es una de las formas en que sus diversas ecologías cotidianas se hacen visibles para sí mismas y para el mundo. Estas ecologías están a favor de la protección ambiental, de los niños, y de la protección lingüística, y se basan en un profundo sentido de lugar forjado a través de lógicas comunitarias horizontales. Nicholas Mirzoeff (293) argumenta que la expansión contemporánea del activismo visual en todo el mundo proviene de un sentido generalizado de que "ellos no nos representan" (en múltiples sentidos del término "representar"). El "activismo visual" emprendido por los Rama Kriol está orientado a la producción de "nuevas formas de ver y ser visto" y "nuevas formas de ver el mundo" (Mirzoeff 297).

\section{Ignorancia e ilegibilidad}

En la coyuntura actual en Nicaragua tanto la democracia como el autoritarismo se encuentran en un estado precario. Como todas las crisis coyunturales, no hay manera de saber cómo y cuándo se resolverá esta crisis. Es complicado porque se trata de cosmovisiones y modos de poder distintos. La estrategia de Ortega es una altamente calculada, basada en el control tanto del espacio como de los recursos. Su objetivo es reprimir cualquier desafío a su liderazgo y su longevidad en el poder e impedir la plena autonomía de la Costa Caribe que pondría en tela de juicio la ideología mestiza sobre la que se asienta el Estado nicaragüense y que acabaría con las estrategias de acumulación capitalista de Ortega.

Si se consideran las tácticas represivas, el secretismo extremo del Gobierno, la creación de desastres ambientales y el desprecio egoísta del Estado de derecho, es difícil entender cómo el FSLN sigue en el poder. No obstante, según el trabajo de Linsey McGoey (2007) y Veena Das (2004), es posible observar cómo la ignorancia y la ilegibilidad se despliegan como armas estratégicas. McGoey sugiere que fingir ignorancia puede ser útil en las burocracias contemporáneas donde la gente espera transparencia. De acuerdo con este modelo, cada afirmación de no saber hecha por el bloque de poder puede ser vista como "aberraciones del procedimiento correcto en lugar de ser endémico al propio sistema" (McCoey 218), particularmente porque existe dentro de un aluvión de comunicación oficialista feliz. Del mismo modo, según investigaciones en la India, Das (245) pregunta cómo el Estado puede 
"reclamar legitimidad frente a falsificaciones claras, corrupción dentro de sus propios procedimientos" y argumenta que "la lógica burocrática desplaza nociones de irracionalidad y pánico a un público crédulo y se construye así como "racional" en su ausencia deliberada de transparencia". En otras palabras, es a través de la creación deliberada de ilegibilidad que el Estado ilegítimo reproduce su propia legitimidad. Pero, como recuerda Das, esta estrategia solo tiene éxito hasta cierto punto, porque la ilegibilidad produce vacíos y ausencias en que los excluidos pueden "insertarse" y producir "nuevas modalidades de gobierno".

Cada vez más los espacios de ignorancia y ausencia creados por el FSLN y consolidados por los medios oficiales están siendo llenados por un activismo de medios sociales de abajo hacia arriba que está alimentando la crisis coyuntural que aflige al estado nicaragüense. Como argumenta Stuart Hall et al. (xii), los bloques hegemónicos dependen del poder cultural para dar "a los acontecimientos un significado social, y para convencer a la sociedad de 'su definición de la situación'”. La necesidad del gobierno de desplegar fuerzas antidisturbios y amenazar a los periodistas señala el fracaso de los discursos y marcos de significado preferidos por sandinistas, porque distan mucho de las experiencias generadas desde otras posiciones dentro de la formación social. El uso de la violencia por parte del Estado hacia las poblaciones indígenas, negros y disidentes indica así un cambio en la estrategia hegemónica a lo largo del contínuum gramsciano del poder que va desde el consentimiento a la coerción.

En consecuencia, las fuerzas antidisturbios se despliegan cada vez más rutinariamente bajo la apariencia de una policía ordinaria, los líderes miskitos son acusados de crímenes ficticios y los periodistas son amenazados; mientras que las narrativas positivas sobre el estado de la nación circulan por las plataformas de medios oficiales sandinistas. Pero si las definiciones sandinistas de situaciones y eventos no tienen resonancia con las experiencias cotidianas de la gente común y no brindan la posibilidad de formas alternativas de conocimiento, es probable que su autoridad se debilite y la formación social continúe fracturándose.

No deberíamos dar por hecho que la cultura popular de los pueblos subordinados constituya un espacio utópico que automáticamente posee los recursos para imaginar un futuro diferente (Rowe y Shelling). Pero lo que sí es cierto es que hay conocimientos alternativos en Nicaragua que han sobrevivido contra todo pronóstico y el entorno mediático actual proporciona acceso a espacios en los que estos conocimientos pueden ser articulados y hacerlo puede ayudar a perseguir objetivos políticos y culturales (aunque no sin riesgo como hemos observado). Los conocimientos puestos en circulación a través del activismo mediado por negros e indígenas frente a la colonialidad, la agnotología y la represión son, como otros conocimientos populares, "compuestos de antagonismos e inestables elementos" (Hall 2006 [1981] 484). 
Se puede ver cómo los Costeños combinan cosmovisiones miskitas y negras con discursos anticapitalistas y anticomunistas y con anti-racismos esencialistas y antiesencialistas. También utilizan estratégicamente las nociones europeas de derecho y ciudadanía, aunque de maneras indigenizadas y hibridizadas, y a veces reproducen las fantasías ambientalistas occidentales de los pueblos indígenas como salvadores de la naturaleza. Afirman sus derechos como nicaragüenses mientras que también construyen a Nicaragua como un territorio extranjero habitado no por los mestizos sino por los españoles. A veces incluso miran nostálgicamente a la dictadura de Somoza. Esta falta de coherencia no debe entenderse como una forma de debilidad política, ya que produce una ilegibilidad propia que hace difícil que el bloque de poder sandinista realice efectivamente su lucha por una hegemonía continuada. Si los discursos de Costeño parecen "políticamente incoherentes" desde el punto de vista de "alianzas políticas tradicionales y oposiciones políticas", es porque las cosmovisiones costeñas ponen en tela de juicio las alianzas políticas convencionales mestizas (Kipnis 387). De hecho, son espacios discursivos heterogéneos que constituyen lo que Enrique Dussel llamaría alteridad, en el sentido de que los Costeños están pensando y hablando desde la exterioridad relativa. Como sostiene Ramón Grosfoguel, siguiendo a Dussel, hay epistemologías que han sobrevivido a la modernidad eurocéntrica, aunque de manera relativa e impura. Significa, sin embargo, que estas epistemologías constituyen un recurso para la construcción de proyectos descoloniales y transmodernos, que las poblaciones subordinadas pueden tomar ideas como la democracia y los derechos humanos "secuestrados" por el Occidente y "descolonizarlos en diferentes direcciones" (Grosfoguel 41). El uso reiterado del lenguaje jurídico como el texto y la terminología de la Ley N. ${ }^{\circ} 445$ en el discurso cotidiano en combinación con narrativas pluriversales es prueba de la construcción de una descolonialidad transmoderna.

\section{Notas}

1 Este estudio se publicó en inglés varios meses antes de las protestas de abril de 2018. En parte, el trabajo explica algunos de los antecedentes y anticipa lo ocurrido después.

2 Algunos de estos "árboles" fueron derribados en las protestas en contra del Gobierno, en abril de 2018.

Este periodista fue asesinado en abril de 2018, mientras informaba sobre las protestas en contra del Gobierno.

La emisora de Yapti Tasba fue quemada por turbas sandinistas varios meses después.

Como escribe Rivera Cusicanqui: "el mundo indígena no comprende la historia como lineal; el pasado-futuro se contiene en el presente" (96). 


\section{Bibliografía}

Adams, P. (2015) "The case of the missing laureate: The communication geography of the 2010 Nobel Peace Prize". Mediated Geographies and Geographies of Media. Eds. S. Mains, J. Cupples y C. Lukinbeal Dordrecht. New York: Springer, 2015. 313-327.

Almanza, R. y Cruz J. D. “La vida en El Carmen”. La Prensa. 18 de agosto de 2013. Recuperado de http://www.laprensa.com.ni/2013/08/18/seccion-domingo/158973-la-vida-en-elcarmen

Antonio, M. (2008) “¿De quiénes y para quiénes son las tierras costeñas?” Envío. 321 (2008). Recuperado de http://www.envio.org.ni/articulo/3904

Bangkukuk, Taik. [YouTube]. “Bangkukuk Taik an indigenous Rama community and the Nicaraguan interoceanic grand canal”. 2015. Recuperado de https://www.youtube.com/ watch? $\mathrm{v}=\mathrm{IIM}-\mathrm{D}-\mathrm{-}-2 \mathrm{lb} 4$

Bangkukuk, Taik. [Vimeo]. “We Do Not Consent! - The indigenous struggle against the Grand Canal of Nicaragua". 2016. Recuperado de https://vimeo.com/174291184

Carballo, W., Chavarría Molina, R. A., Cristancho Cuesta, A., Jover Segura, A., Meza Meetabel, D., Oliva, K., Orozco, Patricia Amanda y Andrade, P. A. “El silencio agrede a Centroamérica". Entre la censura y la discriminación: Centroamérica amenazada. Diagnóstico sobre violaciones a los derechos humanos de periodistas y medios comunitarios de la región. San Salvador: Fundación Comunicándonos, 2014. 3-15.

Carroll R. "Intellectuals condemn authoritarian Ortega". The Guardian. 24 de junio de 2008. Recuperado de http://www.theguardian.com/world/2008/jun/24/2

Castells, M. "Communication, power and counter-power in the network society". International Journal of Communication, 1 (2007): 238-266.

Castells, M. Networks of Outrage and Hope: Social Movements in the Internet Age. Cambridge: Polity, 2012.

Cejudhcan derechos humanos. [YouTube]. "Documental CEJUDHCAN". 2015a. Recuperado de https://www.youtube.com/watch?v=uSiByOazZ9Y

Cejudhcan derechos humanos. [YouTube]. "Deadly conditions on the Miskito Coast". 2015b. Recuperado de https://www.youtube.com/watch?v=jDMdPHQ-Jd0

Cejudhcan derechos humanos. [YouTube]. "Situación del territorio indígena Wangki Twi Tasba Raya". 2015c. Recuperado de https://www.youtube.com/watch?v=lG4D9HF1KXo

Cejudhcan derechos humanos. [YouTube]. "Adolescentes indígenas piden ayuda a través de su canto ante la invasión de colonos". 2015d. Recuperado de https://www.youtube.com/ watch? $\mathrm{v}=$ fbi6Qk8rUI0

Cenidh Nicaragua. [YouTube]. "Juan Herbacio, Presentador la Revista La Voz de la Verdad, Radio Yapti -Tasba, Bilwi". 2015. Recuperado de https://www.youtube.com/ watch?v=uFvNNk_e3RI

Chamorro, E. “Ejército habría emboscado a indígenas en Waspam”. La Prensa. 16 de septiembre de 2015. Recuperado de http://www.laprensa.com.ni/2015/09/16/nacionales/1902585ejercito-embosca-a-indigenas

Confidencial. [YouTube]. "Denuncian de ilegal el acuerdo de arrendamiento para la construcción del canal interoceánico". 2016. Recuperado de https://www.youtube.com/ watch?v=uaR07qkKzGw 
Cupples, J. y Glynn, K. “Postdevelopment television? Cultural citizenship and the mediation of Africa in contemporary TV drama". Annals of the Association of American Geographers 103, 4(2013): 1003-1021.

Cupples, J. y Glynn, K. “The mediation and remediation of disaster: Hurricanes Katrina and Felix in/and the new media environment". Antipode 46, 2(2014): 359-381.

Das, V. "The signature of the state: The paradox of illegibility". Anthropology in the Margins of the State. Comps. V. Das y D. Poole. Santa Fe: School of American Research Press, 2004. 225-254.

Dussel E. Filosofia de Liberación. México: Edicol, 1977.

De Sousa Santos B. "The World Social Forum: Toward a counter-hegemonic globalization" (Part I). World Social Forum: Challenging Empires. Comps. J. Sen, A. Anand, A. Escobar y P. Waterman. New Delhi: Viveka Foundation, 2004. 235-245.

De Sousa Santos B. Epistemologies of the South. Boulder: Paradigm Publishers, 2014.

Duncan, Q. El Pueblo Afrodescendiente: Diálogos con el Abuelo Juan Bautista Yayah. Bloomington: Palibrio, 2012.

Fiske, J. Power Plays, Power Works (2 ${ }^{\text {nd. }}$ Ed). London: Routledge. 2016a.

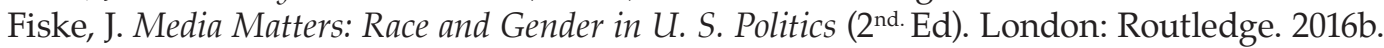

Funez, S. [YouTube]. "Conflicto entre miskitos y colonos". 2015. Recuperado de https://www. youtube.com/watch?v=5js3h2bINO4

Grosfoguel, R. "Epistemic racism/sexism, westernized universities and the four genocides/epistemicides of the long sixteenth century". Eurocentrism, Racism and Knowledge. Comps. S. Rodríguez Maeso y M. Araújo. Basingstoke: Palgrave Macmillan, 2015. 23-46.

Gross, M. y McGoey, L. (2015) “Introduction”. The Routledge International Handbook of Ignorance Studies. Comps. M. Gross y L. McGoey. Abingdon: Routledge, 2015. 1-14

Grossman, C. "Awas Tingni v. Nicaragua: A landmark case for the Inter-American system". Human Rights Brief 8, 3(2001): 2-4.

Hall, S. "Notes on deconstructing the popular". Cultural Theory and Popular Culture: A Reader (3. ${ }^{\text {er }}$ ed.). Comp. J. Storey. Harlow: Pearson, (2006 [1981]). 477-487.

Hall, S., Critcher, C., Jefferson, T., Clarke, J. y Roberts B. Policing the Crisis: Mugging, the State

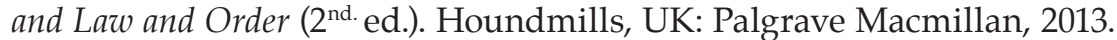

Hooker, J. "Indigenous inclusion/black exclusion: Race, ethnicity and multicultural citizenship in Latin America". Journal of Latin American Studies 37, 2(2005a): 285-310.

Hooker, J. “'Beloved enemies': Race and official mestizo nationalism in Nicaragua". Latin American Research Review 40, 3(2005b): 14-39.

Jenkins, H. Convergence culture: Where Old and New Media Collide. New York: NYU Press, 2006.

Jenkins, H., Ford, S. y Green, J. Spreadable Media: Creating Value and Meaning in a Networked Culture. New York: NYU Press, 2013.

Joel EMC. [YouTube]. "Situación actual del periodismo en la Costa Caribe de Nicaragua”. 2016. Recuperado de https://www.youtube.com/watch?v=8GHvCtubHGQ

Kipnis, L. "(Male) desire and (female) disgust: Reading Hustler". Cultural Studies. Comps. L. Grossberg, C. Nelson y P. Treichler. New York: Routledge, 1992. 373-391.

La Prensa. [YouTube]. "Denuncia de periodistas ante el CENIDH". 2015. Recuperado de https://www.youtube.com/watch?v=YwPKGIgqXE8

Leyden-Sussler, L. "Nicaragua: On the brink of dictatorship". World Policy Blog. 26 de febrero de 2014. Recuperado de http://www.worldpolicy.org/blog/2014/02/25/nicaraguabrink-dictatorship 
Madrid, R. L., Hunter, W. y Weyland, K. “The policies and performance of the contestatory and moderate left". Leftist Governments in Latin America: Successes and Shortcomings. Cambridge: Cambridge University Press, 2010. 140-180.

Mairena, D. Demarcación y titulación de territorios indígenas: La reivindicación de derechos ancestrales. Bilwi: Centro para la Autonomía y Desarrollo de los Pueblos Indígenas, 2014.

Martín-Barbero, J. "From Latin America: Diversity, globalization and convergence". Westminster Papers in Communication and Culture 8, 2 (2011): 39-64.

McGoey, L. "On the will to ignorance in bureaucracy". Economy and Society 36, 2(2007): 212-235.

Mignolo, W. The Idea of Latin America. Malden: Blackwell, 2005.

Mills, C. "Global white ignorance". The Routledge International Handbook of Ignorance Studies. Comps. M. Gross y L. McGoey. Abingdon: Routledge, 2015. 217-227.

Mirzoeff, N. How to See the World. London: Penguin, 2015.

Navas, L. “Ortegaescondióinvasión detierras". LaPrensa. 28 de septiembre de2015. Recuperadode http://www.laprensa.com.ni/2015/09/28/nacionales/1909618-ortega-escondio-invasion-de-tierras

Navarro, A. "Hambre y abandono en comunidades RAAN". Confidencial. 16 de octubre de 2015. Recuperado de http://confidencial.com.ni/hambre-y-abandono-en-comunidades-raan/

Olivares, I. "Gobierno impone un 'apagón informativo'”. Confidencial. 6 de octubre de 2015. Recuperado de http://confidencial.com.ni/gobierno-oculta-datos-de-pobreza/

Onda Local. [YouTube]. "Carlos Wilson Billis". 2016a. Recuperado de https://www.youtube. $\mathrm{com} /$ watch? $\mathrm{v}=$ ny-mbVj_9ZU

Onda Local. [YouTube]. "Monkey Point Allen Clair". 2016b. Recuperado de https://www.youtube.com/watch?v=R2Y6VzRN8eQ

Onda Local. [YouTube]. "Bankukuk Taik Comunitarios". 2016c. Recuperado de https://www. youtube.com/watch?v=104uSBFj34I

Orozco, P. y López, J. “Nicaragua: La relativa calma”. Entre la censura y la discrimación: Centroamérica amenazada: Diagnóstico sobre violaciones a los derechos humanos de periodistas y medios comunitarios de la región. Comps. Carballo, W., Chavarría Molina, R. A., Cristancho Cuesta, A., Jover Segura, A., Meza Meetabel, D., Oliva, K., Orozco, Patricia Amanda y Andrade, P. A. San Salvador: Fundación Comunicándonos, 2014. 127-180.

Prado Reyes, Y. "Firman acuerdo de consentimiento para uso de tierras del Gobierno Territorial Rama y Kriol. 19 Digital. 3 de mayo de 2016. Recuperado de http://www. el19digital.com/articulos/ver/titulo:41492-firman-acuerdo-de-consentimiento-parauso-de-tierras-del-gobierno-territorial-rama-y-kriol

Proctor, R. N. y Schiebinger, L. "Preface". Agnotology: The Making and Unmaking of Ignorance. Stanford: Stanford University Press, 2008. vii-viii.

Quijano, A. “Coloniality and modernity/rationality". Cultural Studies 21, 2-3 (2007): 168-178.

Rezaye Álvarez, M. "Ramas y Kriol denuncian acuerdo ilegal con el Gobierno". La Prensa. 3 de mayo de 2016. Recuperado de http://www.laprensa.com.ni/2016/05/03/ nacionales/2028754-ramas-kriol-denuncian-acuerdo-ilegal-gobierno

Rivera Cusicanqui, S. "Ch'ixinakax utxiwa: A reflection on practices and discourses of decolonization". South Atlantic Quarterly 111, 1 (2012): 95-109. 
Romero, E. “Dos muertos, tres heridos y tres secuestrados tras ataque de colonos a comunidades indígenas de Waspam". La Prensa. 18 de diciembre de 2015. Recuperado de http:// www.laprensa.com.ni/2015/12/18/departamentales/1956617-nuevo-enfrentamientoentre-colonos-e-indigenas

Romero, E., Garth, J. y Álvarez, L. "Gobierno niega crisis indígena ante CIDH". La Prensa. 22 de octubre de 2015. Recuperado de http://www.laprensa.com.ni/2015/10/22/ departamentales/1923376-gobierno-niega-crisis-indigena-ante-cidh

Rothshuh Villanueva, G. Estado de la libertad de la expresión en Nicaragua. Managua: Observatorio de Medios-CINCO, 2014.

Rowe, W. y Schelling, V. Memory and Modernity: Popular Culture in Latin America. London: Verso, 1991.

Sáenz, M. "Dussel on Marx: Living labor and the materiality of life". Thinking from the Underside of History: Enrique Dussel's Philosophy of Liberation. Comps. L. M. Alcoff y L. Mendieta. Lanham: Rowman y Littlefield, 2000. 213-248.

Silva, J. A. "Claves para entender el conflicto en el Caribe Norte. La Prensa. 17 de septiembre de 2015. Recuperado de http://www.laprensa.com.ni/2015/09/17/reportajesespeciales/1903452-claves-para-entender-el-conflicto-en-el-caribe-norte

Smith, A. "Nicaragua's slip back to authoritarianism". Global Public Square. 10 de noviembre de 2011. Recuperado de http://globalpublicsquare.blogs.cnn.com/2011/11/10/nicaraguasslip-back-to-authoritarianism/

Vílchez, D. "Censura policial, ataque a la libertad de prensa". Confidencial. 26 de octubre de 2015. Recuperado de http://confidencial.com.ni/censura-policial-ataque-a-la-libertadde-prensa/

Zibechi R. Dispersing Power: Social Movements as Anti-State Forces. Oakland: AK Press, 2010.

Zibechi R. Territories in Resistance: A Cartography of Latin American Social Movements. Oakland: AK Press, 2012.

Julie Cupples. Británica. Geógrafa, obtuvo su licenciatura y maestría en las universidades de Bradford y Newcastle en el Reino Unido y su doctorado en la Universidad de Canterbury en Nueva Zelandia. Actualmente es catedrática de geografía humana y estudios culturales en la Universidad de Edimburgo en Escocia. Entre 2002 y 2012 trabajó como docente y profesora en la Universidad de Canterbury y en 2017 empeño un cargo de profesora honoraria en Victoria University of Wellington, ambas en Nueva Zelandia. Lleva muchos años haciendo investigaciones y trabajo de campo en Nicaragua y ha publicado muchos artículos sobre la política cultural de Nicaragua, los cuales tocan temas como el género, los desastres y el riesgo ambiental, los procesos electorales, la energía y los medios de comunicación. Es autora o compiladora de seis libros: Latin American Development (Routledge, 2013), Mediated Geographies/Geographies of Media (Springer, 2015), Communications/Media/Geographies (Routledge, 2017) Shifting Nicaraguan 
Mediascapes: Authoritarianism and the Struggle for Social Justice (Springer, 2018) Unsettling Eurocentrism in the Westernized University (Routledge, 2018) y The Routledge Handbook of Latin American Development (Routledge, próximo).

Contacto: julie.cupples@ed.ac.uk

ORCID: 0000-0002-6126-6190

Kevin Glynn: Estadounidense y neozelandés. Recibió su licenciatura, maestría y doctorado de la Universidad de Wisconsin-Madison y ha publicado ampliamente en medios de comunicación y estudios culturales. Actualmente es profesor asociado en la Universidad de Northumbria en el Reino Unido y anteriormente ha ocupado cargos académicos en la Universidad de Massey y la Universidad de Canterbury en Nueva Zelanda, donde cofundó y dirigió el único programa de grado en estudios culturales del país. Es autor de Tabloid Culture: Trash Taste, Popular Power and The Transformation of American Television (Duke University Press) y coautor de Communications/Media/Geographies (Routledge) y Shifting Nicaraguan Mediascapes:Authoritarianism and the Struggle for Social Justice (Springer). Su trabajo también ha aparecido en muchas revistas y antologías internacionales destacadas.

Contacto: kevin.glynn@northumbria.ac.uk

ORCID: 0000-0002-0601-5444 
